\title{
Lithium and GSK3- $\beta$ Promoter Gene Variants Influence White Matter Microstructure in Bipolar Disorder
}

\author{
Francesco Benedetti*,1,2, Irene Bollettini ${ }^{1,2}$, Ignazio Barberi ${ }^{3}$, Daniele Radaelli ${ }^{1,2}$, Sara Poletti ${ }^{1,2}$, \\ Clara Locatelli', , Adele Pirovano', Cristina Lorenzi', Andrea Falini ${ }^{2,4}$, Cristina Colombo' and \\ Enrico Smeraldi ${ }^{1,2}$
}

IIstituto Scientifico Ospedale San Raffaele, Department of Clinical Neurosciences, Scientific Institute and University Vita-Salute, San Raffaele Turro, Milan, Italy; ${ }^{2}$ C.E.R.M.A.C. (Centro di Eccellenza Risonanza Magnetica ad Alto Campo), University Vita-Salute San Raffaele, Milan, Italy; ${ }^{3}$ Dottorato in Neuroscienze e Disturbi del Comportamento, Dipartimento di Scienze Farmacologiche, Università degli Studi di Palermo, Milan, Italy; ${ }^{4}$ Department of Neuroradiology, Scientific Institute and University Vita-Salute San Raffaele, Milan, Italy

Lithium is the mainstay for the treatment of bipolar disorder (BD) and inhibits glycogen synthase kinase 3- $\beta$ (GSK3- $\beta$ ). The less active GSK3- $\beta$ promoter gene variants have been associated with less detrimental clinical features of BD. GSK3- $\beta$ gene variants and lithium can influence brain gray matter structure in psychiatric conditions. Diffusion tensor imaging (DTI) measures of white matter (WM) integrity showed widespred disruption of WM structure in BD. In a sample of 70 patients affected by a major depressive episode in course of $\mathrm{BD}$, we investigated the effect of ongoing long-term lithium treatment and GSK3- $\beta$ promoter rs334558 polymorphism on WM microstructure, using DTI and tract-based spatial statistics with threshold-free cluster enhancement. We report that the less active GSK3$\beta$ rs334558*C gene-promoter variants, and the long-term administration of the GSK3- $\beta$ inhibitor lithium, were associated with increases of DTI measures of axial diffusivity (AD) in several WM fiber tracts, including corpus callosum, forceps major, anterior and posterior cingulum bundle (bilaterally including its hippocampal part), left superior and inferior longitudinal fasciculus, left inferior fronto-occipital fasciculus, left posterior thalamic radiation, bilateral superior and posterior corona radiata, and bilateral corticospinal tract. AD reflects the integrity of axons and myelin sheaths. We suggest that GSK3- $\beta$ inhibition and lithium could counteract the detrimental influences of BD on WM structure, with specific benefits resulting from effects on specific WM tracts contributing to the functional integrity of the brain and involving interhemispheric, limbic, and large frontal, parietal, and fronto-occipital connections.

Neuropsychopharmacology (2013) 38, 313-327; doi: I0.1038/npp.2012.172; published online 19 September 2012

Keywords: GSK3- $\beta$; lithium; bipolar disorder; white matter; cingulum bundle

\section{INTRODUCTION}

Glycogen synthase kinase $3-\beta$ (GSK3- $\beta$ ) is an essential element of the Wnt/beta-catenin pathway, which is involved in the control of gene expression, cell behavior, cell adhesion, and cell polarity, and has major roles in neurodevelopment and regulation of neuronal polarity, neuronal plasticity, and cell survival (Grimes and Jope, 2001b). GSK3- $\beta$ is constitutively active and regulates the activity of many targets, including transcriptional factors, enzymes and cytoskeletal proteins (Kockeritz et al, 2006). GSK3- $\beta$ is considered a primary regulator in a range of cellular processes, including differentiation, growth, motility, and apoptosis: increasing GSK3 activity increases apoptosis in neuronal cells, whereas inhibiting GSK has neuroprotective effects (Forde and Dale,

*Correspondence: Dr F Benedetti, Istituto Scientifico Ospedale San Raffaele, Department of Clinical Neurosciences, Scientific Institute and University Vita-Salute, San Raffaele Turro, Via Stamira d'Ancona 20, Milan 20125, Italy, Tel: + 3902 26433 I56, Fax: + 3902 26433265, E-mail: benedetti.francesco@hsr.it

Received 5 June 2012; revised 25 July 2012; accepted 2 August 2012
2007). GSK3 is then considered a key factor in influencing the susceptibility of neurons to harmful stimuli (neuronal resilience) (Manji et al, 2000). Its inhibitory phosphorilation occurs in response to neurotrophins, such as brain-derived neurotrophic factor (BDNF), or to insulin or insulin-like growth factor, or to secreted Wnt glycoproteins (Gould and Manji, 2005).

Control of the phosphorylation/activity status of GSK3- $\beta$ is considered an important mechanism of serotonin (5-HT) and dopamine (DA) action on brain and behavior (Beaulieu et al, 2008). Converging studies in animal models showed that inhibition of GSK3- $\beta$ occurs in the context of the signaling cascades in response to lithium, valproate, and several antidepressants, such as selective 5-HT reuptake inhibitors, monoamine oxidase inhibitors, and tricyclic antidepressants, thus affirming an involvement of GSK3- $\beta$ in the regulation of behavior by the main drugs used in the treatment of bipolar disorder (BD) (Beaulieu et al, 2009; Gould and Manji, 2005). Lithium, in particular, can inhibit GSK3- $\beta$ both directly, by competing with magnesium, and indirectly, by increasing its phosphorylation state via inhibition of a protein phosphatase that normally activates 
GSK3- $\beta$ (Jope, 2003). These mechanisms are likely to have a key role in the neuroprotective effects of lithium (Quiroz et al, 2010) and could be an essential part of the mechanism of its therapeutics action in BD by correcting a proposed impairment of cellular plasticity and resilience (Bachmann et al, 2005).

To study the role of GSK3- $\beta$ in BD, we and other groups performed association studies bewteen core characteristics of the illness and a promoter SNP ( $-50 \mathrm{~T} / \mathrm{C}$; rs334558), which in cultured human embryonic kidney HEK293 and human neuroblastoma SK-N-MC cell lines was associated with a significant 1.4-fold increase in transcriptional strength of the wild $\mathrm{T}$ allele relative to the $\mathrm{C}$ allele, because the $\mathrm{C}$ allele abrogates the binding of the activating enhancer-binding protein 4 (AP4) transcriptional factor (Kwok et al, 2005). The low-activity C allele was associated with less detrimental clinical features of mood disorders, including a delayed onset of illness (Benedetti et al, 2004a), a better clinical response to lithium in the lifetime prevention of illness recurrences (Benedetti et al, 2005), and a better antidepressant response both to lithium augmentation therapy of drug-resistant depressive episodes (Adli et al, 2007) and to non-pharmacological antidepressant treatment with sleep deprivation (Benedetti et al, $2004 \mathrm{~b})$. Genetic variation of GSK3- $\beta$ activity was shown to modulate the effects of genetic determinants of monoaminergic function: in rodents, the knockout of GSK3- $\beta$ counteracted the depressive-like behavioral effects of genetic 5-HT inhibition (Beaulieu et al, 2008); in depressed bipolar patients, either carrying the $\mathrm{rs} 334558^{*} \mathrm{C}$ allele (Benedetti et al, 2012) or being administered therapeutic doses of lithium (Benedetti et al, 2008) could overcome the detrimental influence of the short form of the 5-HT promoter on antidepressant response.

GSK3- $\beta$ gene variants and lithium can influence brain structure in psychiatric conditions. $\mathrm{rs} 334558^{*} \mathrm{C}$ itself was associated with protective effects against gray matter (GM) loss in schizophrenia (Benedetti et al, 2010), whereas other SNPs either directly related to GSK3- $\beta$, or to its substrate proteins, were associated with GM volumes in major depressive disorder (Inkster et al, 2009, 2010). Lithium administration was followed by an increase of GM volumes in healthy humans (Monkul et al, 2007) and in patients affected by BD (Bora et al, 2010), thus possibly counteracting GM volume reductions in critical cortical areas (Benedetti et al, 2011b). Pivotal prospective studies confirmed that the lithium-associated GM volume increase during treatment correlated with treatment response in $\mathrm{BD}$ (Lyoo et al, 2010; Moore et al, 2009).

In recent years, diffusion tensor imaging (DTI) techniques allowed to study the microstructure of white matter (WM) in vivo. Given the microscopic structure of WM, in normal conditions the integrity of myelinated axons limits the diffusion of water in directions other than along the main axis of the fiber (axial diffusivity (AD)). This tendency to diffuse in one direction as opposed to all others, termed anisotropy, can be estimated through the application of diffusion-sensitizing gradients and the calculation of elements of the diffusion tensor matrix, ie, the three eigenvalues $\lambda_{1}, \lambda_{2}$, and $\lambda_{3}$. (Basser et al, 1994; Le Bihan, 2003; Taylor et al, 2004). A decrease of the tendency to diffuse along the principal direction $\left(\lambda_{1}\right)$ of the fiber, 'axial diffusivity', suggests axonal loss or loss of bundle coherence, and an increase in 'radial diffusivity' (the average of $\lambda_{2}$ and $\lambda_{3}$ ), perpendicular to axonal walls, suggests disrupted myelination (Song et al, 2002). Mean diffusivity (MD, average of $\lambda_{1}, \lambda_{2}$, and $\lambda_{3}$ ) is a measure of the average molecular motion, independent of tissue directionality. Fractional anisotropy (FA) is the square root of the sum of squares (SRSSs) of the diffusivity differences, divided by the SRSS of the three diffusivities, with values ranging between 0 and 1 depending on directionality of diffusivity.

Notwithstanding the many studies of BD performed on mixed samples of patients with heterogeneous illness phases and drug treatments, independent studies in selected samples showed widespread changes of DTI measures in untreated depressed patients (Benedetti et al, 2011c), drugnaive patients with mania (Adler et al, 2006), untreated patients with first episode psychosis (Lu et al, 2011), and high-risk unaffected relatives of patients with BD (Sprooten et al, 2011). Although these studies documented a widespread increased diffusivity perpendicular to axonal walls, with reduced FA in some areas, during illness phases of opposite polarity, the few observations in stable euthymic patients showed changes in the opposite direction, with increased FA in patients with $\mathrm{BD}$ compared with controls (Houenou et al, 2007; Wessa et al, 2009). These results suggested that WM diffusivity changes in $\mathrm{BD}$ might be of clinical relevance, with DTI providing new markers to estimate the susceptibility to the disorder, to identify new targets for treatment, and to predict and monitor treatment efficacy.

The influence of GSK3- $\beta$ and lithium on brain structure could extend to the WM of bipolar patients, as also suggested by our preliminary observations of a normalizing effect of lithium on the WM tracts connecting amygdala and subgenual cingulate (Benedetti et al, 2011a), and by a study on twins showing that lithium could be protective against the lobar WM loss associated with BD (van der Schot et al, 2009). GSK3- $\beta$ inhibition by lithium and other compounds promotes differentiation of oligodendrocytes from their precursors, myelination, and remyelination of lesions in the brain (Azim and Butt, 2011), as well as, in other districts, recovery of spinal lesions (Dill et al, 2008) and differentiation and myelination of Schwann cells (Ogata et al, 2004). Consistent data showed that GSK3- $\beta$ is critical for establishing neuronal polarity, promoting neurite outgrowth, and turning mature neurites into axons in CNS neurons (Yoshimura et al, 2005). Axonal formation and elongation has been observed in vitro in cultured mature neurons derived from adult mammals when inhibiting GSK3- $\beta$ with lithium or other compounds, and in vivo in spinal cord lesioned rats also treated with lithium, thus suggesting that the role of GSK3- $\beta$ and lithium in regulating the inherent growth ability of neurons extends to mature cells (Dill et al, 2008). These effects have been linked with the ability of GSK to influence the phosphorylation status of several microtubule-binding proteins and to promote the assembly of microtubules (Dill et al, 2008; Zhou et al, 2004).

Given that DTI is sensitive to factors affecting myelin and axonal microstructure (Kinoshita et al, 1999), we hypothesized that GSK3- $\beta$ promoter gene variants and lithium, which can influence axonal structures in mature neurons, could also influence DTI measures of the tendency of water 
to diffuse into the brain, and in particular along the principal direction of the WM fibers $\left(\mathrm{AD}, \lambda_{1}\right)$, which has been shown to be a marker specifically sensitive to axonal integrity and damage (Boretius et al, 2012). We tested this hypothesis in the present study performed on a homogeneous sample of patients affected by a major depressive episode in course of bipolar illness and either drug-free or treated with lithium salts.

\section{MATERIALS AND METHODS}

\section{Participants}

We studied 70 consecutively admitted inpatients affected by a major depressive episode, without psychotic features, with a diagnosis of BD type I (structured clinical interview for DSM disorders). Patients were either drug-free $(n=50)$ or on treatment with lithium $(n=20)$. Exclusion criteria were: additional diagnoses on axis I, mental retardation on axis II, pregnancy, major medical and neurological disorders, history of drug or alcohol abuse, or dependency. Physical examination, laboratory tests, and electrocardiograms were performed at admission. No patient had received electroconvulsive therapy within 6 months prior to study enrollment. Duration of illness and lifetime duration of lithium treatment in months were assessed by the psychiatrist in charge and an independent interviewer using best estimation procedure, taking into account available charts, case notes, and informations provided by at least one relative (Leckman et al, 1982). Handedness was assessed with the Edinburgh inventory (Oldfield, 1971). After complete description of the study to the participants, written informed consent was obtained. The study was approved by the local Ethical Committee.

\section{Genotyping}

To genotype rs334558, DNA was extracted from whole blood by a manual extraction, using the Illustra blood genomicPrep Midi Flow kit (GE Healthcare, Milan, Italy). PCR was performed with these primers: $5^{\prime}$-GACGTCCGTGATT GGCTC- $3^{\prime}$ and $5^{\prime}$-AGCCCAGAG CCCTGTCAG-3'. The PCR reaction was carried out in $10 \mu \mathrm{l}$ volume containing $150 \mathrm{ng}$ genomic DNA, $5 \mathrm{pM}$ of each primer, $200 \mu \mathrm{M}$ each $\mathrm{dNTP}, 10 \times$ HotMaster Taq Buffer, $5 \mathrm{U}$ of HotMaster Taq DNA Polymerase (Eppendorf, Milan, Italy), and $0.5 \mu \mathrm{l}$ of dimethyl sulfoxide solution (Sigma-Aldrich, Milan, Italy). After an initial step of $2 \mathrm{~min}$ at $94^{\circ} \mathrm{C}, 35$ cycles of amplification (20 s at $94{ }^{\circ} \mathrm{C}, 10 \mathrm{~s}$ at $60^{\circ} \mathrm{C}, 25 \mathrm{~s}$ at $70^{\circ} \mathrm{C}$ ) and a final extension step of $10 \mathrm{~min}$ at $70^{\circ} \mathrm{C}$ were performed. An aliquot of PCR product was digested using AluI (New England Biolabs, England, UK); fragments were separated in agarose gels. Unrestricted PCR product (CC genotype) had a size of $344 \mathrm{bp}$; complete restriction (TT genotype) produces two bands of 220 and 124 bp.

In the light of the rare frequency of the mutant rs334558 $\mathrm{C} / \mathrm{C}$ homozygote genotype, analyses were performed by comparing rs334558 T/T wild-type homozygotes with pooled heterozygote and homozygote carriers of the mutant $\mathrm{C}$ allele. This approach was justified by previous observations showing that (a) heterozygotes and homozygote carriers of the $\mathrm{C}$ allele showed similar differences from
T/T homozygotes in the acute (Adli et al, 2007) and longterm (Benedetti et al, 2005) clinical response to lithium, which targets GSK3- $\beta$, and that (b) the effect on GM in schizophrenia was the same in $\mathrm{T} / \mathrm{C}$ and $\mathrm{C} / \mathrm{C}$, which both differed from T/T (Benedetti et al, 2010), thus suggesting that all $\mathrm{C}$ carriers could share the same biological reactivity to these challenges.

\section{Image Acquisition}

DTI was performed on a 3.0 Tesla scanner (Gyroscan Intera, Philips, the Netherlands) using SE Eco-planar imaging and the following parameters: TR/TE $=8753.89 / 58 \mathrm{msec}$, FoV (mm) 231.43 (ap), 126.50 (fh), 240.00 (rl); acquisition matrix $2.14 \times 2.71 \times 2.31 ; 55$ contiguous, $2.3-\mathrm{mm}$ thick axial slices reconstructed with in-plane pixel size $1.88 \times 1.87 \mathrm{~mm}^{2}$; SENSE acceleration factor $=2 ; 1$ b0 and 35 non-collinear directions of the diffusion gradients; $b$ value $=900 \mathrm{sec} / \mathrm{mm}^{2}$. Fat saturation was performed to avoid chemical shift artifacts. On the same occasion and using the same magnet 22 Turbo Spin Echo, T2 axial slices ( $\mathrm{TR}=3000 \mathrm{~ms}$; $\mathrm{TE}=85$ ms; flip angle $=90^{\circ}$; turbo factor $15 ; 5-\mathrm{mm}$ thick axial slices with a $512 \times 512$ matrix and a $230 \times 230 \mathrm{~mm}^{2}$ field of view) were acquired to rule out brain lesions.

\section{Data Processing and Analyses}

Image analyses and tensor calculations were done using the 'Oxford Center for Functional Magnetic Resonance Imaging of the Brain Statistical Library' (FSL 4.1.4; www.fmrib.ox.ac.uk/fsl/index.html) (Smith et al, 2004; Woolrich et al, 2009). First, each of the 35 DTI volumes was affine registered to the $\mathrm{T} 2$-weighted $\mathrm{b}=0$ volume using FLIRT (FMRIB's Linear Image Registration Tool) (Jenkinson and Smith, 2001). This corrected for motion between scans and residual eddy-current distortions present in the diffusionweighted images. In addition, trained reasearchers blind to diagnosis manually inspected each volume of each image to check for head motion artifacts: scans rated as 0 (none) had little or no detectable motion artifact, those rated as 1 (mild) had enough detectable motion to result in subtle concentric bands, 2 (moderate) had significant banding, whereas those rated as 3 (severe) were so extreme that the data were deemed unreliable for analyses (Blumenthal et al, 2002). After removal of nonbrain tissue (Smith, 2002), least-square fits were performed to estimate the FA, eigenvector, and eigenvalue maps. MD was defined as the mean of all three eigenvalues $\left(\left(\lambda_{1}+\lambda_{2}+\lambda_{3}\right) / 3\right), \mathrm{AD}$ as the principal diffusion eigenvalue $\left(\lambda_{1}\right)$, and RD as the mean of the second and third eigenvalues $\left(\left(\lambda_{2}+\lambda_{3}\right) / 2\right)$.

Next, all individuals' volumes were skeletonized and transformed into a common space as used in tract-based spatial statistics (Smith et al, 2006; Smith et al, 2007). TBSS focuses on the centers of all fiber bundles that are common to the participants (the most compact WM skeleton), thus improving the probability that the given spatial voxels contain data from the same part of the same WM tract of each participant. Briefly, all volumes were nonlinearly warped to the FMRIB58_FA template supplied with FSL (http://www.fmrib.ox.ac.uk/fsl/tbss/FMRIB58_FA.html) and normalized to the Montreal Neurological Institute (MNI) space, by use of local deformation procedures performed by 
FMRIB's NonLinear Image Registration Tool (FNIRT) (www.fmrib.ox.ac.uk/fsl/fnirt/index.html), a nonlinear registration toolkit using a b-spline representation of the registration warp field (Rueckert et al, 1999). The common template used in the present study is a high-resolution average of $58 \mathrm{FA}$ volumes from healthy male and female subjects aged 20-50 years. All warped FA volumes were visually inspected for accuracy, which is especially pertinent when analyzing data sets with broad age ranges with relatively large interindividual variability in brain size and architecture. FNIRT has been shown to perform the native-to-standard warping adequately across several age groups, including children and adolescents (Westlye et al, 2010). Next, a mean FA volume of all subjects was generated and thinned to create a mean FA skeleton representing the centers of all common tracts. We thresholded and binarized the mean skeleton at $\mathrm{FA}>0.20$ to reduce the likelihood of partial voluming in the borders between tissue classes, yielding a mask of 137833 WM voxels. Individual FA values were warped onto this mean skeleton mask by searching perpendicular from the skeleton for maximum FA values. Using maximum FA values from the centers of the tracts further minimizes confounding effects attributable to partial voluming (Smith et al, 2006). The resulting tract invariant skeletons for each participant were fed into voxelwise permutationbased cross-subject statistics. Similar warping and analyses were used on $M D, A D$, and $R D$ data sampled from voxels with FA $>0.20$.

To investigate the effect of GSK3- $\beta$ rs334558, we ran a permutation-based nonparametric inference to investigate the differences between the two groups of $\operatorname{rs} 334558^{\star} \mathrm{C}$ carriers and T/T homozygotes. Given that lithium showed progressive effects on GM structure during treatment in $\mathrm{BD}$ (Lyoo et al, 2010; Moore et al, 2009), to investigate the effect of lithium, we correlated the duration of lithium treatment in months with DTI measures of WM microstructure. We accounted for the effects of nuisance covariates which could influence WM structure: age (Kochunov et al, 2007), sex (Herting et al, 2011), and age at onset of illness. Voxelwise DTI analyses were performed using nonparametric permutation-based testing (Nichols and Holmes, 2002) as implemented in randomized FSL. We tested for linear effects of genotype and of lithium on FA, MD, AD, and RD across the WM skeleton with general linear models (GLMs). Threshold-free cluster enhancement (TFCE) (Smith and Nichols, 2009) was used to avoid defining arbitrary clusterforming thresholds and smoothing levels. TFCE is particularly useful when the spatial correlation length of signal exceeds that of noise, as it is expected when studying WM tracts. It can be seen as a generalization of the cluster mass statistics (Bullmore et al, 1999), using spatial neighborhood information in a nonlinear image processing to increase sensitivity and boosting the height of spatially distributed signals, without changing the location of their maxima. Voxelwise levels of significance, corrected for multiple comparisons, were then calculated with a standard permutation testing by building up the null distribution (across permutation of the input data) of the maximum (across voxels) TFCE scores, and then using the 95th percentile of the null distribution to threshold signals at corrected $p<0.05$. The data were tested against an empirical null distribution generated by 5000 permutations for each contrast, thus providing statistical maps fully corrected for multiple comparisons across space. Corrected $p<0.05$ in a minimum cluster size of $\mathrm{k}=100$ was considered significant.

To confirm and estimate effect sizes, values were then extracted at signal peaks and compared among genotype groups with an analysis of variance (ANOVA) performed in the context of the GLM (McCulloch et al, 2008; Timm and Kim, 2006). The independent variables were GSK3- $\beta$ rs334558 genotype (between groups) and localization of the clusters (within groups), the DTI measures in the peak difference voxels were the dependent variables, and age was considered as nuisance covariate. The significance of the effect of the single factors on the dependent variables was estimated (least squares method) by parametric estimates of predictor variables and following the standard computational procedures (Hill and Lewicki, 2006).

\section{RESULTS}

Clinical and demographic characteristics of the sample are shown in Table 1.

No difference was statistically significant. The distribution of genotypes was T/T 26/70 (37.1\%), T/C 34/70 (48.6\%), and C/C 10/70 (14.3\%), thus respecting the Hardy-Weinberg equilibrium $\left(\chi^{2}=0.043, p=0.834\right)$. Allelic frequencies (T $61.4 \%$ and C $38.6 \%$ ) were closely similar to those previously observed in healthy subjects (Russ et al, 2001) and in patients affected by BD (Benedetti et al, 2004b, Benedetti et al, 2005) or schizophrenia (Benedetti et al, 2010).

GSK3- $\beta$ rs334558 influenced DTI measures (Table 2). We observed increases of $\mathrm{AD}$ and $\mathrm{MD}$ in $\mathrm{C}$ carriers compared with T/T homozygotes, in most part of the brain WM tracts (Figure 1).

Differences in $\mathrm{AD}$ were observed in three main clusters, which included corpus callosum, cingulum bundle (including its hippocampal part), uncinate fasciculus, superior and inferior longitudinal fasciculus, corona radiata, and thalamic radiation (see listing in Table 2). AD values extracted from the three signal peaks (Figure 2) were entered the GLM ANOVA, which confirmed a global highly significant effect of $\mathrm{rs} 334558$ on $\mathrm{AD}$ values $(\mathrm{F}=16.29 ; \mathrm{df}=1,67 ; p=0.0001$. Effect size: partial $\eta^{2}=0.20$, power $\left.=0.98\right)$, which was significant in every cluster ( $\mathrm{L}$ Corona Radiata: $\mathrm{F}=6.88$; $\mathrm{df}=1,67 ; p=0.0108 . \mathrm{R}$ Corona Radiata: $\mathrm{F}=9.53 ; \mathrm{df}=1,67 ;$ $p=0.0029$; R Superior Longitudinal Fasciculus: $\mathrm{F}=5.46$; $\mathrm{df}=1,67 ; p=0.0224$ ).

The values of $\mathrm{AD}$ in the three clusters significantly differed $(\mathrm{L}>\mathrm{R}$, and Corona Radiata $>\mathrm{SLF} ; \mathrm{F}=5.145 ; \mathrm{df}=2$, $134 ; p=0.0070$ ), but there was no significant interaction of rs334558 and localization, thus suggesting that the effect of GSK3- $\beta$ rs334558 was homogeneous in these regions.

Lithium influenced DTI measures (Table 3). Duration of lithium treatment positively correlated with $\mathrm{AD}$ and $\mathrm{MD}$ in several WM tracts, mainly in the left hemisphere (Figure 3).

Differences in $\mathrm{AD}$ were observed in two main clusters, which included several of the tracts where an influence of GSK was detected: callosum, cingulum, uncinate, superior 
Table I Clinical and Demographic Characteristics of the Sample Divided According to GSK3- $\beta$ rs334558 Genotype and Ongoing Lithium Treatment

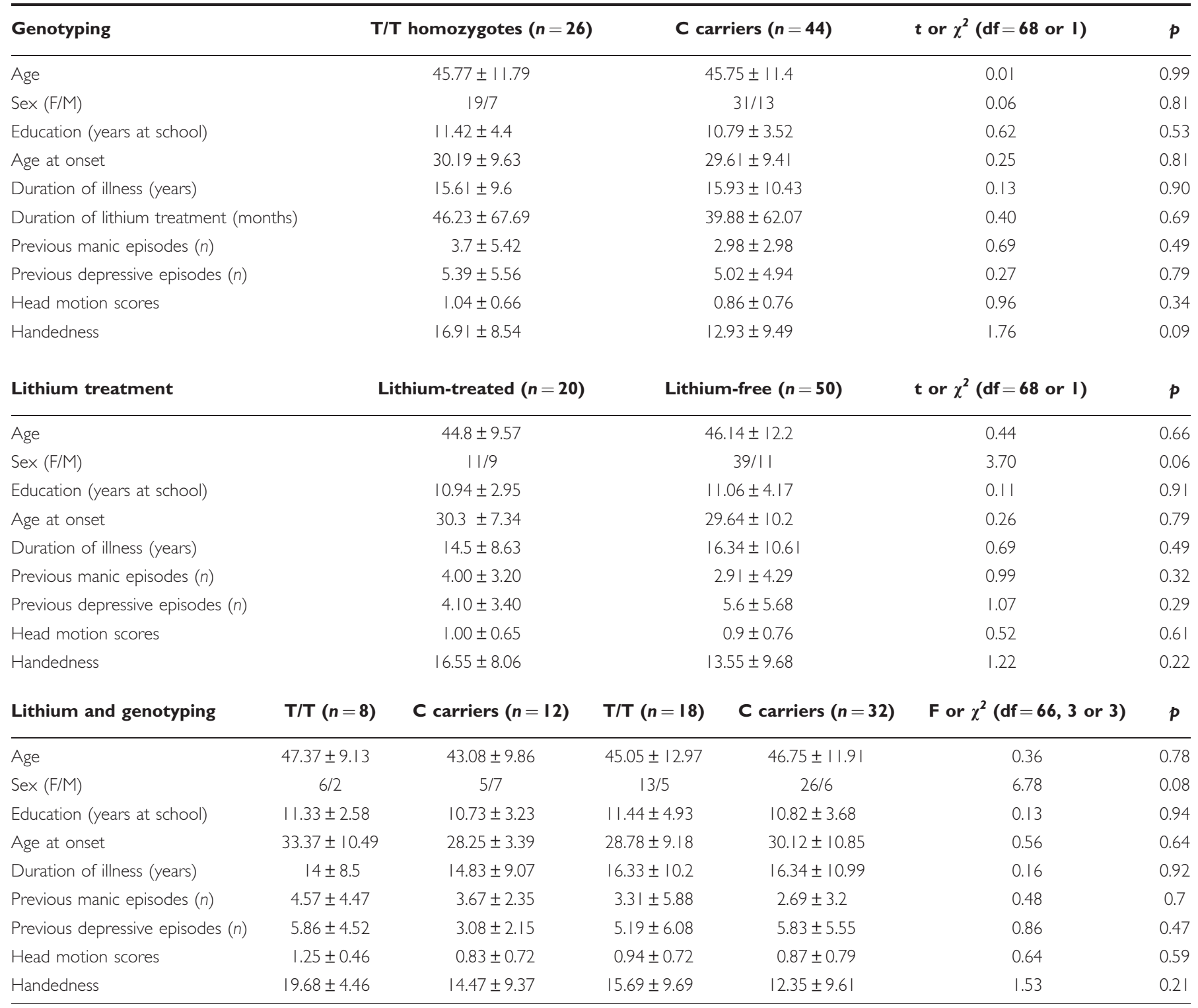

No difference was statistically significant (Student's t-test, one-way ANOVA, or $\chi^{2}$ test as appropriate).

and inferior longitudinal fasciculi, and corona radiata (see listing in Table 3). Values extracted from the signal peak (at $24-5427$ ) and from the body of the callosum (at 016 19) significantly correlated with duration of lithium treatment (Figure 4: $r=0.347, p=0.00325$ and $r=0.481, p=0.000025$, respectively).

The effects of GSK3- $\beta$ rs334558 and lithium on AD overlapped in several tracts. The WM tracts where both factors had a significant effect (see Figure 5) were corpus callosum, forceps major, anterior and posterior cingulum bundle (bilaterally including its hippocampal part), left superior and inferior longitudinal fasciculus, left inferior fronto-occipital fasciculus, left posterior thalamic radiation, bilateral superior and posterior corona radiata, and bilateral corticospinal tract.

No significant effect was observed for FA and RD values in any analysis.

\section{DISCUSSION}

We observed that the less active GSK3- $\beta$ rs $334558^{*} \mathrm{C}$ genepromoter variants, and the long-term administration of the GSK3- $\beta$ inhibitor lithium, were associated with increases of DTI measures of $\mathrm{AD}$ and $\mathrm{MD}$ in WM fiber tracts. The increase of MD was likely driven by the increase of $\mathrm{AD}$, given that $\mathrm{RD}$ was not significantly influenced by the two factors.

$\mathrm{AD}$ represents the water diffusivity parallel to the axonal fibers, reflecting the greater freedom of water to diffuse along the principal fiber axis rather than to travel across the surrounding myelin sheaths. Both myelin and axonal microstructure, including microtubules and neurofilaments (Kinoshita et al, 1999), contribute to this diffusion anisotropy. Studies on neurodevelopment associated AD with fiber diameter or organization (Takahashi et al, 2000). 
Table 2 Comparison of GSK3- $\beta$ rs $334558^{*}$ C Carriers with T/T Homozygotes

\begin{tabular}{lcc}
\hline Axial diffusivity & $\begin{array}{c}\text { No. of voxels and } \\
\text { signal peaks } \\
(\mathrm{X}, \mathrm{Y}, \mathrm{Z})\end{array}$ & $\begin{array}{c}\text { White matter } \\
\text { tracts }\end{array}$ \\
&
\end{tabular}

\begin{tabular}{lll}
\hline $\mathrm{T} / \mathrm{T}=11.92 \pm 1.59$ & 7618 & Forceps minor \\
$\mathrm{C}$ carriers $=$ & $-20-1740$ & Genu of corpus callosum \\
$12.37 \pm 1.6$ & $(\mathrm{~L}$ corona radiata) & Body of corpus callosum
\end{tabular}

$12.37 \pm 1.6 \quad$ (L corona radiata)

Splenium of corpus callosum Forceps major

Cingulum bundle Uncinate fasciculus $L$

Superior longitudinal fasciculus $L$ Inferior longitudinal fasciculus $L$ Inferior fronto-occipital fasciculus L

Anterior thalamic radiation $L$ Corticospinal tract $L$

Anterior corona radiata $L$

Superior corona radiata $L$

Posterior corona radiata $L$

$3114 \quad$ Forceps minor

$21-2640 \quad$ Body of corpus callosum

( $R$ corona radiata) Cingulum bundle $\mathrm{R}$

Superior longitudinal fasciculus $R$

Superior corona radiata $\mathrm{R}$

Corticospinal tract $\mathrm{R}$

$\begin{array}{ll}2740 & \text { Splenium of corpus callosum } \\ 37-4430 & \text { Forceps major } \\ \text { (R superior } & \text { Cingulum bundle } R\end{array}$

( $R$ superior Cingulum bundle $R$

longitudinal fasciculus) Hippocampus $\mathrm{R}$

Superior longitudinal fasciculus $R$ Inferior longitudinal fasciculus $R$ Posterior thalamic radiation $\mathrm{R}$ Inferior fronto-occipital fasciculus $\mathrm{R}$

\begin{tabular}{|c|c|c|}
\hline Mean diffusivity & $\begin{array}{l}\text { No of voxels and } \\
\text { signal peaks } \\
(X, Y, Z)\end{array}$ & $\begin{array}{l}\text { White matter } \\
\text { tracts }\end{array}$ \\
\hline \multirow[t]{3}{*}{$\begin{array}{l}\mathrm{T} / \mathrm{T}=7.3 \pm 0.38 \\
\mathrm{C} \text { carriers }= \\
7.56 \pm 0.35\end{array}$} & $\begin{array}{l}2620 \\
-262026 \\
\text { (L uncinate fasciculus) }\end{array}$ & $\begin{array}{l}\text { Forceps minor } \\
\text { Body of corpus callosum } \\
\text { Cingulum } L \\
\text { Uncinate fasciculus } L \\
\text { Inferior fronto-occipital fasciculus } \\
L \\
\text { Anterior thalamic radiation } L \\
\text { Corticospinal tract } L \\
\text { Superior corona radiata } L\end{array}$ \\
\hline & $\begin{array}{l}1820 \\
23-137 \\
\text { (R posterior limb of } \\
\text { internal capsule) }\end{array}$ & $\begin{array}{l}\text { Cerebral peduncle } R \\
\text { Posterior limb of internal capsule } \\
R \\
\text { Corticospinal tract } R \\
\text { External capsule } R \\
\text { Anterior thalamic radiation } R \\
\text { Anterior limb of internal capsule } \\
\text { Superior longitudinal fasciculus } R\end{array}$ \\
\hline & $\begin{array}{l}286 \\
-282332 \\
\text { (L anterior thalamic } \\
\text { radiation) }\end{array}$ & Superior longitudinal fasciculus $L$ \\
\hline
\end{tabular}

In the first column, values of the DTI measures of AD and MD (means $\pm S D$ ) are given for for regions showing maximal differences of TBSS values (signal peak). The second column shows dimensions of clusters (number of voxels, $\mathrm{mm}^{3}$ ) and localization of signal peaks (MNI coordinates). The third column lists the WM tracts significantly affected by genotype in the clusters.
Animal models associated a reduction of $\mathrm{AD}$ with axonal injury (Boretius et al, 2012; Song et al, 2003; Sun et al, 2006), and conversely associated an increase of RD with unchanged AD with dysmyelination (Song et al, 2002). Over the human lifespan, $\mathrm{AD}$ and $\mathrm{MD}$ decrease initially, and then increase later in life (Lebel et al, 2012; Qiu et al, 2008), also reflecting changes in fiber coherence and tortuosity (Dubois et al, 2008).

The effects of lithium and rs334558 overlapped in most part of the affected WM tracts, thus suggesting possible common neurobiological mechanisms. Given that lithium inhibits GSK, and the rs $334558^{*} \mathrm{C}$ allele has been associated with a lower expression of GSK, these common mechanisms could directly involve GSK3- $\beta$ activity or its substrate proteins. Several non-alternative mechanisms could contribute to the converging effects of the GSK3- $\beta$ promoter polymorphism and lithium on $\mathrm{AD}$ by influencing the characteristics of both myelin and axonal microstructure, which are considered the neurobiological underpinnings of this DTI measure.

Concerning axonal microstructure, GSK3- $\beta$ has a key regulatory role in establishing and mantaining neuronal polarity (Yoshimura et al, 2006; Yoshimura et al, 2005). As summarized in the Introduction section, inhibition of GSK3- $\beta$ by lithium promotes axonal formation and elongation in mature neurons, also promoting the assembly of microtubules (Dill et al, 2008; Namekata et al, 2012; Zhou et al, 2004), which contribute to the preferential diffusion along the principal fiber axis of the fibers (Kinoshita et al, 1999), measured with the eigenvalue $\lambda_{1}$ in DTI. Increasing activity of GSK3- $\beta$ in vitro inhibits axon formation, whereas both lithium and other selective inhibitors of GSK3- $\beta$ cause the formation of multiple axons at the expenses of dendrites, a process probably limited by the availability of membrane and cytoplasmic materials (Jiang et al, 2005). Several mechanisms contribute to this effect. BDNF has a key role in the differentiation and neuritogenesis of developing neurons and in the synaptic plasticity of mature neurons: downstream of BDNF signaling, the axon growth induced by neurotrophins is mediated by localized inactivation of GSK3- $\beta$ (Zhou et al, 2004), which promotes axon branching and microtubule assembly (Namekata et al, 2012), and lithium significantly elevates the expression and production of BDNF in vitro ( $\mathrm{Su}$ et al, 2009) and in vivo (de Sousa et al, 2011; Leyhe et al, 2009). Inhibition of GSK3- $\beta$ by lithium also increases the neurite outgrowth mediated by the neurotrophic pituitary adenylate cyclase-activating polypeptide (Zhang et al, 2009). Lithium-induced neurite outgrowth is also mediated by an increased phosphorylation of extracellular-signal regulated kinases (Wang et al, 2011) and by an upregulated expression of sorting nexin 3 (Mizutani et al, 2009), but the effects of lithium on axonal structures also involve altered levels of expression of genes whose function has not yet been fully elucidated (Italia et al, 2011).

Concerning myelin, GSK3- $\beta$ inhibition by lithium and other compounds promotes differentiation of oligodendrocytes from their precursors, myelination, and remyelination of lesions in the brain (Azim and Butt, 2011). This pivotal study showed that GSK3- $\beta$ inhibition promotes the 

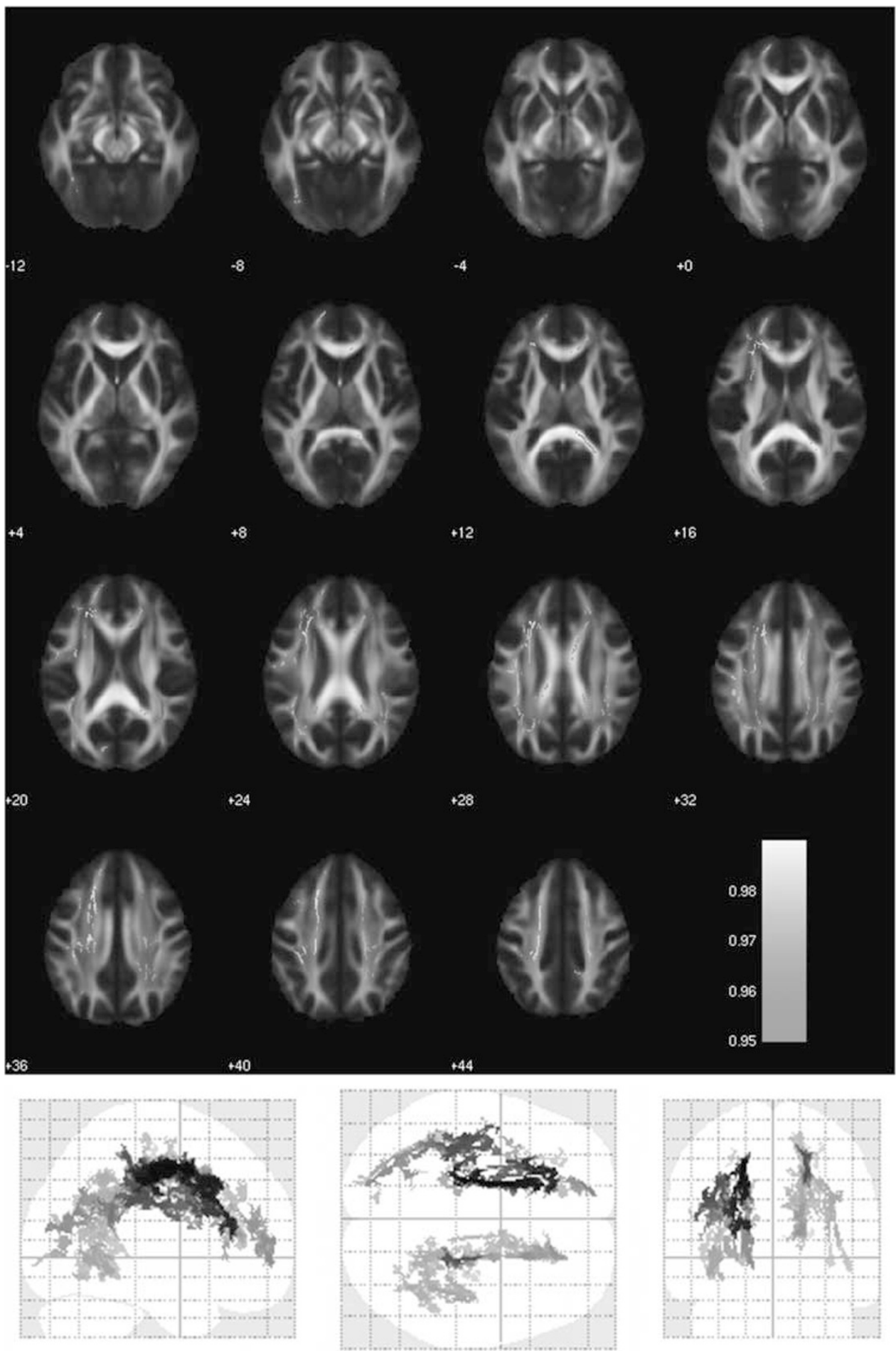

Figure I WM areas where GSK3- $\beta$ rs334558*C carriers showed significantly higher values of axial diffusivity (AD) than T/T homozygotes. Voxels of significant group difference are mapped on the mean FA template of the studied sample and are shown in glass-brain images. The color bar refers to I - $p$ values for the observed differences. Numbers are Z coordinates in the standard Montreal Neurological Institute (MNI) space.

proliferation of oligodendrocytes precursors and their differentiation into mature oligodendrocytes both in vivo in the adult and in the developing brain and ex vivo in organotypic cultures of optic nerve, and confirmed that when GSK3- $\beta$ is inhibited by lithium, these effects involve an interaction between the Wnt pathway and other mechanisms (Azim and Butt, 2011). In particular, GSK3- $\beta$ inhibition increases proliferation of oligodendrocytes precursors via the canonical Wnt- $\beta$-catenin pathway, but Wnt activation then hampers the differentiation of precursors into myelinating oligodendrocytes (Fancy et al, 2009; Feigenson et al, 2009). Direct inhibition of GSK3- $\beta$ by lithium and other compounds, however, enhances activation of the cyclic AMP response element binding (CREB) 


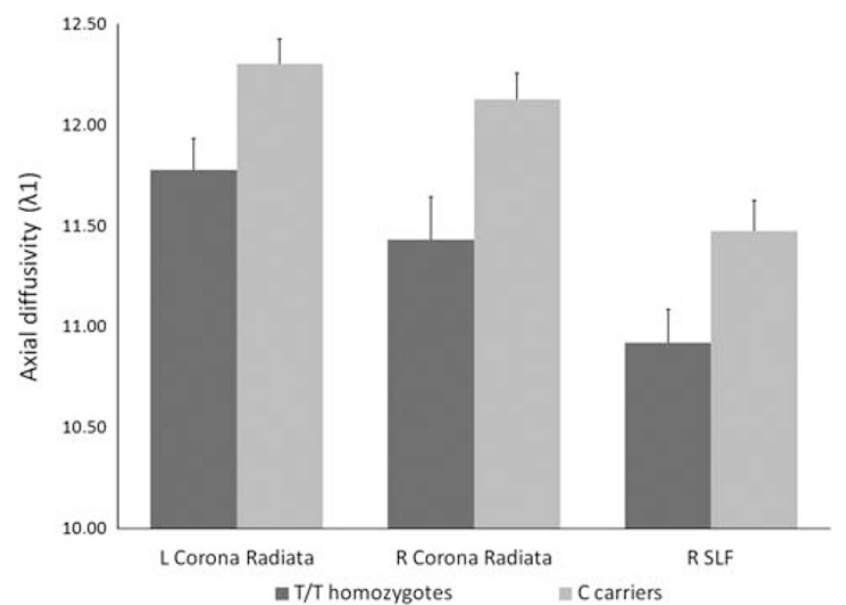

Figure 2 Values of $A D$ extracted at signal peaks in the three clusters where GSK3- $\beta$ rs $334558^{*} \mathrm{C}$ carriers showed significantly higher values of $\mathrm{AD}$ than $\mathrm{T} / \mathrm{T}$ homozygotes. Columns are means, error bars are SEM. Differences among genotypes were significant in all regions.

protein (Grimes and Jope, 2001a), which stimulates oligodendrocytes differentiation (Pende et al, 1997), and decreases Notch1 signaling (Azim and Butt, 2011), which inhibits oligodendrocytes differentiation (Wang et al, 1998): these two mechanisms override the negative effect of Wnt activation on oligodendrocytes differentiation, and the net effect of GSK3- $\beta$ inhibition with lithium then increase both the proliferation of oligodendrocytes precursors and their differentiation into mature oligodendrocytes (Azim and Butt, 2011). Moreover, lithium could influence oligodendrocytes and the lipid composition of myelin by inducing BDNF. BDNF has an impact on the proliferating population of oligodendrocyte lineage cells and regulates the numbers of progenitors and the abilities of cells to express myelin proteins (VonDran et al, 2011), and promotes cholesterol byosynthesis, which is essential for synapse development in cultured neurons (Suzuki et al, 2007) and for myelin generation and repair (Dietschy and Turley, 2004). Postmortem gene expression, neuropathological, and neuroimaging studies suggest downregulation of key oligodendrocyte and myelination genes (Tkachev et al, 2003), as well as lowered number, size, and density of oligodendroglial cells in BD patients (Carter, 2007; Rajkowska, 2002; Uranova et al, 2004). This glial reduction in mood disorders (Manji et al, 2001), paralleled by in vivo changes of DTI measures (Benedetti et al, 2011c) and brain WM volumes, has been associated with the genetic risks to develop BD (van der Schot et al, 2009): GSK3- $\beta$ inhibition by lithium could act as a protective mechanism against these effects.

Several other mechanisms affecting brain cellular structures, and thus modifying the tendency of water to diffuse along the principal axis of the fiber, could be involved as well. Autophagy, one of the principal responses to cellular stress and a core regulator of neuronal survival and function, is promoted by lithium (Chiu and Chuang, 2010). Inhibitors of GSK3- $\beta$, including lithium, can reduce migration of microglia and inflammation-induced neuronal toxicity (Yuskaitis and Jope, 2009), and could then counteract putative inflammation-induced changes of brain DTI measures associated with $\mathrm{BD}$, and which resulted in a loss of diffusion anisotropy (Benedetti et al, 2011c). Adding to its effect on GSK and BDNF, lithium modulates many neurotransmitters and adjusts signaling activities regulating second messengers, transcription factors, and gene expression (Jope, 1999), and it influences many cellular mechanisms involved in neurotrophic and neuroprotective effects, including cyclic adenosine monophosphate (cAMP)mediated signal transduction, CREB activation, the phosphatidylinositide cascade, protein kinase $\mathrm{C}$, and B-cell lymphoma 2 expression (Quiroz et al, 2010). Lithium markedly increases the neuroprotective protein $\mathrm{Bcl}-2$ in the same prefrontal cortical layers where, in patients, a postmortem reduction of neuronal and glial cells has been reported (Chen et al, 1999). Lithium modulates the expression of structural postsynaptic genes with topographic specificity in cortical and subcortical regions, such as Homer, Shank, and Inositol 1,4,5-trisphosphate receptor (de Bartolomeis et al, 2012), and causes quantitative perturbations in postsynaptic density proteome linked to several key signaling pathways (Nanavati et al, 2011). GSK3 inhibition not only affects the Wnt cascade but also influences other mechanisms; eg, it regulates AMPAinduced GluR1 and GluR2 internalization via phosphorylation of kinesin light chain 2, the key molecule of the kinesin cargo delivery system, thus regulating synaptic plasticity and behavior (Du et al, 2010). Akt and GSK3 integrate 5-HT and DA neurotransmission, and also provide a link between the action of these neurotransmitters and gene products, like disrupted in schizophrenia 1 and neuregulin, that are associated with both cell structure and risk for mental illness (Beaulieu, 2012). Moreover, at the cellular level, clock genes could provide a mechanism for the control of circadian gene expression and responsivity to stimuli (Dallaspezia et al, 2011; Kondratov et al, 2006), and GSK3- $\beta$ is a core costituent of the mammalian circadian clock and affects circadian rhythm generation by modifying the stability of circadian clock molecules (Iitaka et al, 2005).

Effects on neural and synaptic plasticity within key circuits have been proposed as core mechanisms of the therapeutic action of lithium (Schloesser et al, 2011), and the hypothesis that changes in WM microstructure could be part of the mechanism of action of lithium is in agreement with data on WM imaging in BD (Brambilla et al, 2009), with recent perspectives emphasizing the therapeutic relevance of the effects of psychotropic drugs on myelination and lipid homeostasis (Bartzokis, 2011; Bartzokis et al, 2009; Vik-Mo et al, 2009), and with recent findings in other psychiatric conditions, suggesting that changes of DTI measures could reflect a yet unexplored part of the mechanism of action of psychotropic drugs (Benedetti et al, 2012).

Existing literature on the relationship between DTI measures, $\mathrm{BD}$, and brain functions suggests that a higher directionality of water diffusion along the main axis of the WM fiber tracts could at least partly explain why lithium treatment and the GSK3- $\beta$ rs $334558^{*} \mathrm{C}$ gene-promoter variant have been associated with less detrimental features of BD. A lower directionality of water diffusion in the same WM tracts where lithium and GSK3- $\beta$ rs $334558^{\star} \mathrm{C}$ increased $\mathrm{AD}$ has been associated with $\mathrm{BD}$ (Benedetti et al, 2011c; $\mathrm{Lu}$ et al, 2011). These localizations include key WM tracts 


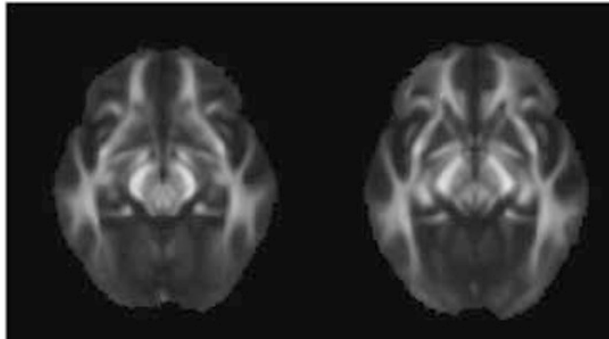

12

$-8$

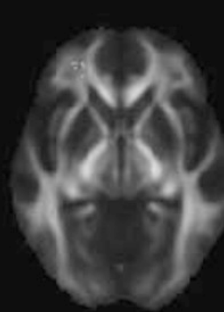

$-4$
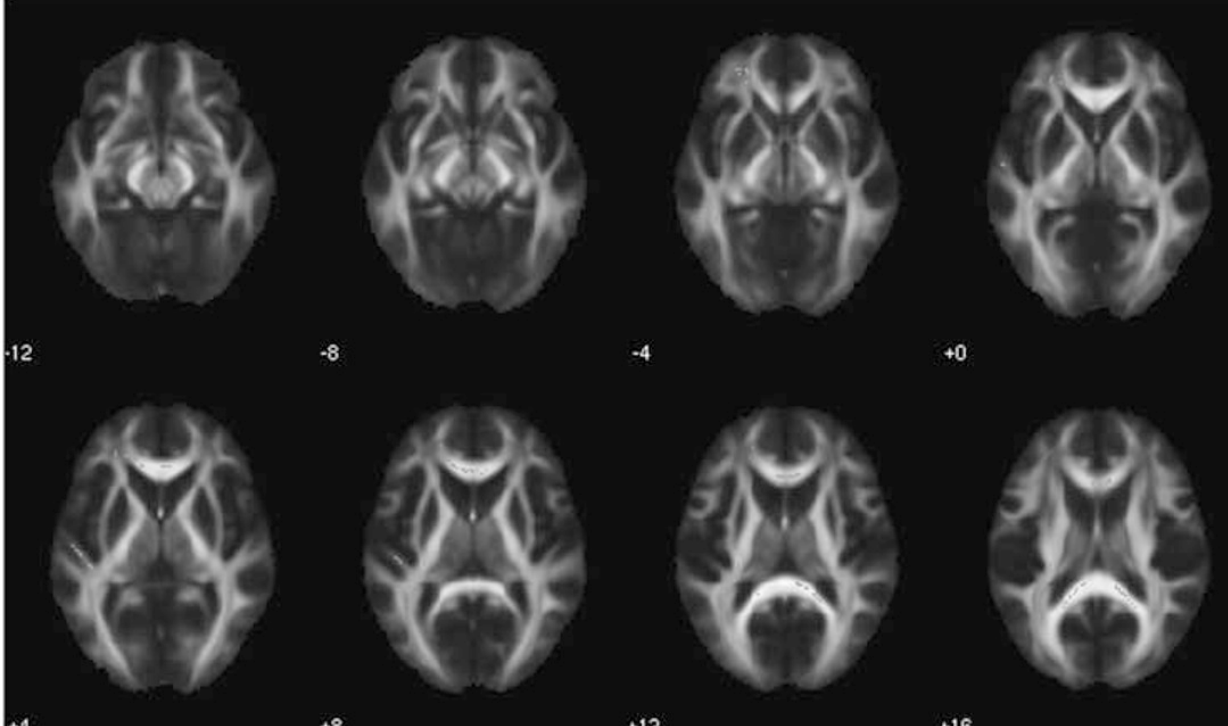

$+0$
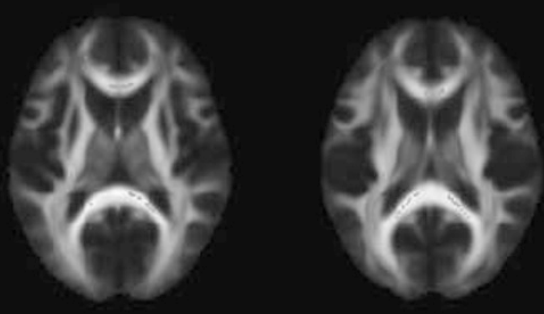

$+12$

$+16$
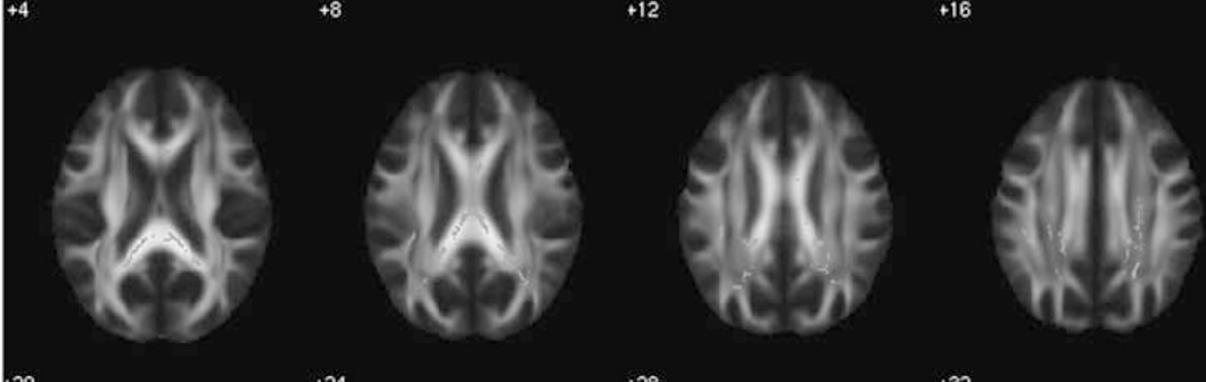

$+20$

24

$+28$
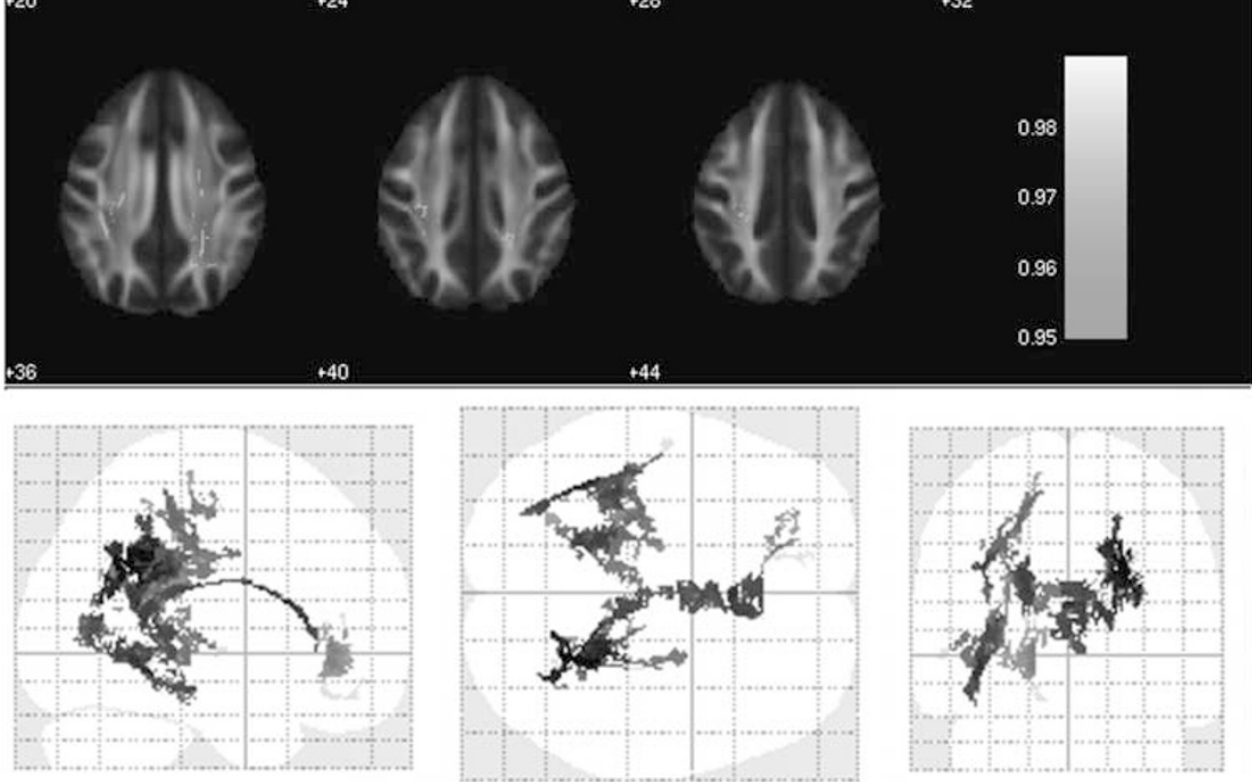

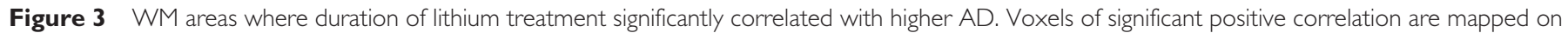

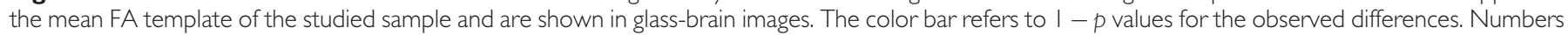
are $Z$ coordinates in the standard $M N I$ space.

contributing to the functional integrity of the brain. Compromised communication involving interhemispheric connections, limbic, and large frontal, parietal, and frontooccipital connections could be a major biological underpinning of the hypothesized brain network dysfunctions, leading to the cognitive and emotional deficits typical of $\mathrm{BD}$
(Brambilla et al, 2009), and could contribute to explain the abnormal effective cortico-limbic connectivity observed with functional MRI in bipolar patients (Arnone et al, 2008; Rich et al, 2008).

Following this perspective and considering our results and existing literature on mood disorders, specific benefits 
Table 3 Correlation of the Duration of Lithium Treatment with DTI Measures

\begin{tabular}{|c|c|c|}
\hline $\begin{array}{l}\text { Axial } \\
\text { diffusivity }\end{array}$ & $\begin{array}{l}\text { No. of voxels and } \\
\text { signal peaks } \\
(X, Y, Z)\end{array}$ & White matter tracts \\
\hline $13.6 \mid \pm 2.37$ & $\begin{array}{l}6196 \\
24-5427 \\
\text { (Inferior fronto-occipital } \\
\text { fasciculus R) }\end{array}$ & $\begin{array}{l}\text { Forceps minor } \\
\text { Genu of corpus callosum } \\
\text { Splenium of corpus callosum } \\
\text { Cingulum bundle } \\
\text { (hippocampus) } R \\
\text { Uncinate fasciculus } L \\
\text { Superior longitudinal fasciculus } L \\
\text { Inferior longitudinal fasciculus } L \\
\text { Inferior fronto-occipital } \\
\text { fasciculus } R \\
\text { Posterior thalamic radiation } L \\
\text { Retrolenticular part of internal } \\
\text { capsule } L \\
\text { Corticospinal tract } L \\
\text { Corticospinal tract } R \\
\text { Superior corona radiata } L \\
\text { Superior corona radiata } R\end{array}$ \\
\hline & $\begin{array}{l}140 \\
-24-4534 \\
\text { Superior longitudinal } \\
\text { fasciculus L }\end{array}$ & $\begin{array}{l}\text { Superior longitudinal fasciculus } L \\
\text { Anterior thalamic radiation } L \\
\text { Cingulum bundle } L\end{array}$ \\
\hline
\end{tabular}

$\begin{array}{lll}\begin{array}{l}\text { Mean } \\ \text { diffusivity }\end{array} & \begin{array}{l}\text { No. of voxels and } \\ \text { signal peaks } \\ (\mathrm{X}, \mathrm{Y}, \mathrm{Z})\end{array}\end{array}$

\begin{tabular}{|c|c|c|}
\hline \multirow[t]{2}{*}{$7.92 \pm 0.64$} & $\begin{array}{l}12289 \\
-11022 \\
\text { (Body of corpus callosum) }\end{array}$ & $\begin{array}{l}\text { Forceps minor } \\
\text { Genu of corpus callosum } \\
\text { Body of corpus callosum } \\
\text { Splenium of corpus callosum } \\
\text { Cingulum bundle } L \\
\text { Cingulum bundle } R \\
\text { Uncinate fasciculus } L \\
\text { Superior longitudinal fasciculus } L \\
\text { Inferior longitudinal fasciculus } L \\
\text { Inferior longitudinal fasciculus } R \\
\text { Inferior fronto-occipital } \\
\text { fasciculus } L \\
\text { Inferior fronto-occipital } \\
\text { fasciculus } R \\
\text { Anterior thalamic radiation } L \\
\text { Corticospinal tract } L \\
\text { Corticospinal tract } R \\
\text { Anterior limb of internal capsule } \\
L \\
\text { Posterior limb of internal } \\
\text { capsule } L \\
\text { Superior corona radiata } L\end{array}$ \\
\hline & $\begin{array}{l}486 \\
51-723\end{array}$ & Superior longitudinal fasciculus $R$ \\
\hline
\end{tabular}

In the first column, values of the DTI measures of AD and MD (means \pm SD) are given for regions showing maximal effects of lithium on TBSS values (signal peaks). The second column shows dimensions of clusters (number of voxels, $\mathrm{mm}^{3}$ ) and localization of signal peaks (MNI coordinates). The third column lists the WM tracts significantly affected by lithium in the clusters.

for patients with $\mathrm{BD}$ could come from an increased $\mathrm{AD}$ in specific WM tracts. Hippocampal dysfunction and atrophy associates with mood disorders (Small et al, 2011), and in normal and neurodegenerative conditions, DTI measures of WM microstrucure of the hippocampal part of the cingulum bundle correlate with memory scores and hippocampal volume (Sexton et al, 2010). The cingulum bundle integrates disparate modular brain systems involved in attention, memory, and emotion regulation, and in mood disorders, a higher directionality of water diffusion in the cingulum bundle associates with better hedonic tone (Keedwell et al, 2012), better cognitive performance (Schermuly et al, 2010), and less psychomotor slowing (Walther et al, 2012). The number of fibers within the uncinate fasciculus inversely correlated with depression severity (Zhang et al, 2012). Executive function and processing speed were correlated with anisotropy of the anterior thalamic radiation and uncinate fasciculus in late life depression (Sexton et al, 2011). Abnormal myelination and morphometry of callosum interhemispheric connections have been consistently associated with $\mathrm{BD}$ (Bearden et al, 2011) and dimensions of BD psychopatology, such as aggression (Saxena et al, 2012) and suicide (Matsuo et al, 2010).

Altogether, these findings support the interest for DTI measures of WM microstructure as individual biomarkers in patients with $\mathrm{BD}$ and confirm the hypothesis that GSK inhibition and lithium could counteract the detrimental influences of BD on WM structure (Benedetti et al, 2011a). These effects on WM could parallel the effects on GM (see Introduction) and contribute to the global benefit for the patient.

Strengths of the present study include a focused research question and state-of-the-art imaging methods, but our results must be viewed in light of several methodological limitations. Animal models of DTI measures have been mainly developed to test toxic, but not therapeutic, effects of drugs (Harsan et al, 2006), and this limits the specificity of diffusion measures for the neurobiological effects of drugs. Sample size allowed to define effects of lithium use and protective GSK3- $\beta$ rs334558 variants in the same brain regions (Figure 5), but did not allow to test specific interactions between the two factors (eg, comparing lithium effects among genotypes or genotype effects among subgroups defined by the duration of the treatment). Again, we obtained an excellent power to study a single polymorphism, but could not consider other gene-gene and gene-environment interactions, and their interaction with clinical variables. There was no placebo control for lithium administration. The duration of lithium treatment was estimated retrospectively, thus being biased by the impossibility to assess compliance. Patients were non drugnaive, and the drug treatments administered during the course of the illness could have influenced DTI measures, alone or interacting with lithium salts. Recruitment was in a single center and in a single ethnic group, thus raising the possibility of population stratifications, limiting the generalizability of the findings.

In conclusion, these limitations do not bias the main finding of overlapping effects of lithium use and protective GSK3- $\beta$ rs334558 in WM tracts, which (1) suggests a shared mechanism to be further confirmed and explored in enlarged and independent samples and (2) confirms the usefulness of DTI for the study of the brain structural changes associated with $\mathrm{BD}$. 

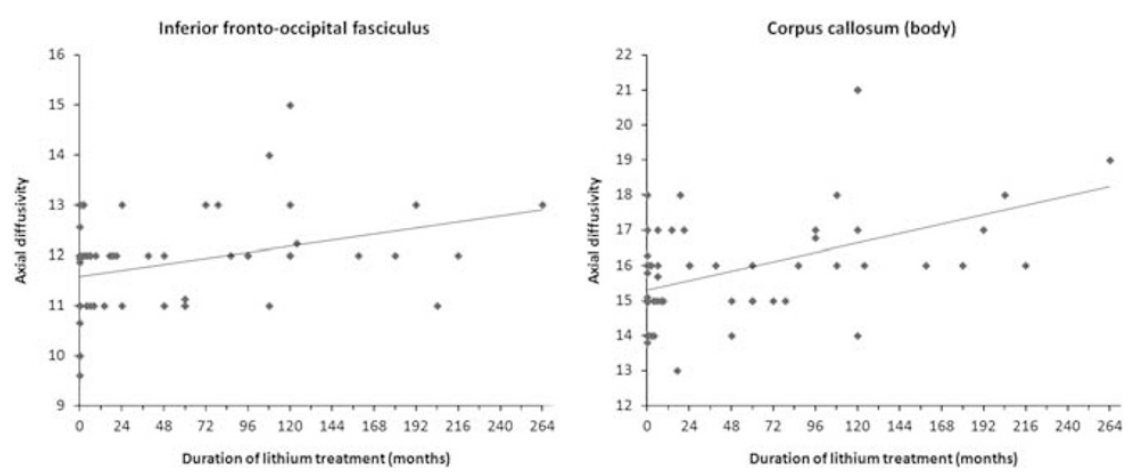

Figure 4 Correlation between AD values and duration of lithium treatment for values extracted at signal peak (MNI $24-5427$ ) and from the body of the callosum (MNI 0 I6 19).

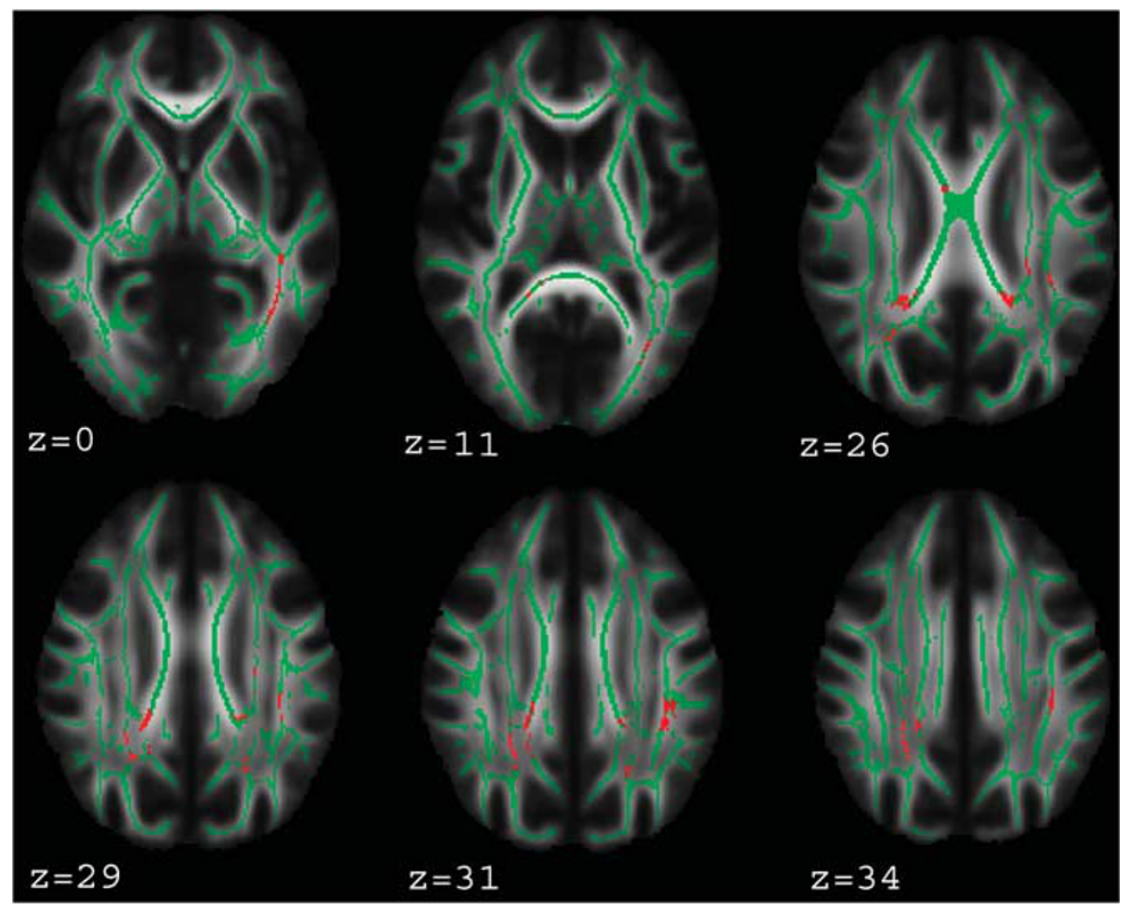

Figure 5 WM areas where both GSK3- $\beta$ rs334558 and duration of lithium treatment influenced AD. Voxels of significant group difference or positive correlation are mapped on the WM skeleton and superimposed on the mean FA template of the studied sample. Numbers are $Z$ coordinates in the standard MNI space.

\section{ACKNOWLEDGEMENTS}

The C.E.R.M.A.C. received research grants from the Italian Ministry of University and Scientific Research, the Italian Ministry of Health, the European Union (FP7 grant 222963), Trenta ore per la Vita Association, and Janssen-Cilag.

\section{DISCLOSURE}

The authors declare no conflict of interest.

\section{Author contributions}

All individuals included as authors of papers contributed substantially to the scientific process, leading up to the writing of the paper. FB designed the study. ES, CC, FB, and $\mathrm{AF}$ obtained the funding. $\mathrm{CL}$ and $\mathrm{CC}$ were involved in participants' recruitment and selection, and collected the clinical data. DR and SP carried out the brain imaging scanning with the neuroradiological supervision of AF. IBo and IBa designed the TBSS-TFCE data analyses and carried it out with contributions from FB. CL and AP performed the genotyping. FB wrote the first draft of the manuscript. All authors take final responsibility for the decision to submit for publication. FB and IB had full access to all of the data in the study and take responsibility for the integrity of the data and the accuracy of the data analysis. The authors are entirely responsible for the scientific content of the paper.

\section{REFERENCES}

Adler CM, Adams J, DelBello MP, Holland SK, Schmithorst V, Levine A et al (2006). Evidence of white matter pathology in bipolar disorder adolescents experiencing their first episode of mania: a diffusion tensor imaging study. Am J Psychiatry 163: $322-324$. 
Adli M, Hollinde DL, Stamm T, Wiethoff K, Tsahuridu M, Kirchheiner J et al (2007). Response to lithium augmentation in depression is associated with the glycogen synthase kinase 3beta $-50 \mathrm{~T} / \mathrm{C}$ single nucleotide polymorphism. Biol Psychiatry 62: $1295-1302$

Arnone D, McIntosh AM, Chandra P, Ebmeier KP (2008). Metaanalysis of magnetic resonance imaging studies of the corpus callosum in bipolar disorder. Acta Psychiatr Scand 118: 357-362.

Azim K, Butt AM (2011). GSK3beta negatively regulates oligodendrocyte differentiation and myelination in vivo. Glia 59: $540-553$.

Bachmann RF, Schloesser RJ, Gould TD, Manji HK (2005). Mood stabilizers target cellular plasticity and resilience cascades: implications for the development of novel therapeutics. Mol Neurobiol 32: 173-202.

Bartzokis G (2011). Neuroglialpharmacology: white matter pathophysiologies and psychiatric treatments. Front Biosci 17: 2695-2733.

Bartzokis G, Lu PH, Stewart SB, Oluwadara B, Lucas AJ, Pantages J et al (2009). In vivo evidence of differential impact of typical and atypical antipsychotics on intracortical myelin in adults with schizophrenia. Schizophr Res 113: 322-331.

Basser PJ, Mattiello J, LeBihan D (1994). MR diffusion tensor spectroscopy and imaging. Biophys J 66: 259-267.

Bearden CE, van Erp TG, Dutton RA, Boyle C, Madsen S, Luders E et al (2011). Mapping corpus callosum morphology in twin pairs discordant for bipolar disorder. Cereb Cortex 21: 2415-2424.

Beaulieu JM (2012). A role for Akt and glycogen synthase kinase-3 as integrators of dopamine and serotonin neurotransmission in mental health. J Psychiatry Neurosci 37: 7-16.

Beaulieu JM, Gainetdinov RR, Caron MG (2009). Akt/GSK3 signaling in the action of psychotropic drugs. Annu Rev Pharmacol Toxicol 49: 327-347.

Beaulieu JM, Zhang X, Rodriguiz RM, Sotnikova TD, Cools MJ, Wetsel WC et al (2008). Role of GSK3 beta in behavioral abnormalities induced by serotonin deficiency. Proc Natl Acad Sci USA 105: 1333-1338.

Benedetti F, Giacosa C, Radaelli D, Poletti S, Dallaspezia S, Pozzi E et al (2012). Widespread changes of white matter microstructure in obsessive-compulsive disorder: Effect of drug status. Eur Neuropsychopharmacol (in press) http://dx.doi.org/10.1016/j. euroneuro.2012.07.002.

Benedetti F, Absinta M, Rocca MA, Radaelli D, Poletti S, Bernasconi A et al (2011a). Tract-specific white matter structural disruption in patients with bipolar disorder. Bipolar Disord 13: 414-424.

Benedetti F, Barbini B, Bernasconi A, Fulgosi MC, Campori E, Colombo $\mathrm{C}$ et al (2008). Lithium overcomes the influence of 5HTTLPR gene polymorphism on antidepressant response to sleep deprivation. J Clin Psychopharmacol 28: 249-251.

Benedetti F, Bernasconi A, Lorenzi C, Pontiggia A, Serretti A, Colombo C et al (2004a). A single nucleotide polymorphism in glycogen synthase kinase 3-beta promoter gene influences onset of illness in patients affected by bipolar disorder. Neurosci Lett 355: 37-40.

Benedetti F, Dallaspezia S, Lorenzi C, Pirovano A, Radaelli D, Locatelli C et al (2012). Gene-gene interaction of glycogen synthase kinase 3-beta and serotonin transporter on human antidepressant response to sleep deprivation. J Affect Disord 136: 514-519.

Benedetti F, Poletti S, Radaelli D, Bernasconi A, Cavallaro R, Falini A et al (2010). Temporal lobe grey matter volume in schizophrenia is associated with a genetic polymorphism influencing glycogen synthase kinase 3-beta activity. Genes Brain Behav 9: 365-371.

Benedetti F, Radaelli D, Poletti S, Locatelli C, Falini A, Colombo C et al (2011b). Opposite effects of suicidality and lithium on gray matter volumes in bipolar depression. J Affect Disord 135: 139-147.
Benedetti F, Serretti A, Colombo C, Lorenzi C, Tubazio V, Smeraldi E (2004b). A glycogen synthase kinase 3-beta promoter gene single nucleotide polymorphism is associated with age at onset and response to total sleep deprivation in bipolar depression. Neurosci Lett 368: 123-126.

Benedetti F, Serretti A, Pontiggia A, Bernasconi A, Lorenzi C, Colombo C et al (2005). Long-term response to lithium salts in bipolar illness is influenced by the glycogen synthase kinase 3-beta -50T/C SNP. Neurosci Lett 376: 51-55.

Benedetti F, Yeh PH, Bellani M, Radaelli D, Nicoletti MA, Poletti S et al (2011c). Disruption of white matter integrity in bipolar depression as a possible structural marker of illness. Biol Psychiatry 69: 309-317.

Blumenthal JD, Zijdenbos A, Molloy E, Giedd JN (2002). Motion artifact in magnetic resonance imaging: implications for automated analysis. Neuroimage 16: 89-92.

Bora E, Fornito A, Yucel M, Pantelis C (2010). Voxelwise metaanalysis of gray matter abnormalities in bipolar disorder. Biol Psychiatry 67: 1097-1105.

Boretius S, Escher A, Dallenga T, Wrzos C, Tammer R, Bruck W et al (2012). Assessment of lesion pathology in a new animal model of MS by multiparametric MRI and DTI. Neuroimage 59: 2678-2688.

Brambilla P, Bellani M, Yeh PH, Soares JC (2009). Myelination in bipolar patients and the effects of mood stabilizers on brain anatomy. Curr Pharm Des 15: 2632-2636.

Bullmore ET, Suckling J, Overmeyer S, Rabe-Hesketh S, Taylor E, Brammer MJ (1999). Global, voxel, and cluster tests, by theory and permutation, for a difference between two groups of structural MR images of the brain. IEEE Trans Med Imaging 18: $32-42$.

Carter CJ (2007). Multiple genes and factors associated with bipolar disorder converge on growth factor and stress activated kinase pathways controlling translation initiation: implications for oligodendrocyte viability. Neurochem Int 50: 461-490.

Chen G, Zeng WZ, Yuan PX, Huang LD, Jiang YM, Zhao ZH et al (1999). The mood-stabilizing agents lithium and valproate robustly increase the levels of the neuroprotective protein bcl-2 in the CNS. J Neurochem 72: 879-882.

Chiu CT, Chuang DM (2010). Molecular actions and therapeutic potential of lithium in preclinical and clinical studies of CNS disorders. Pharmacol Ther 128: 281-304.

Dallaspezia S, Lorenzi C, Pirovano A, Colombo C, Smeraldi E, Benedetti F (2011). Circadian clock gene Per3 variants influence the postpartum onset of bipolar disorder. Eur Psychiatry 26: 138-140.

de Bartolomeis A, Tomasetti C, Cicale M, Yuan PX, Manji HK (2012). Chronic treatment with lithium or valproate modulates the expression of Homer $1 \mathrm{~b} / \mathrm{c}$ and its related genes Shank and Inositol 1,4,5-trisphosphate receptor. Eur Neuropsychopharmacol 22: 527-535.

de Sousa RT, van de Bilt MT, Diniz BS, Ladeira RB, Portela LV, Souza DO et al (2011). Lithium increases plasma brain-derived neurotrophic factor in acute bipolar mania: a preliminary 4week study. Neurosci Lett 494: 54-56.

Dietschy JM, Turley SD (2004). Thematic review series: brain lipids. Cholesterol metabolism in the central nervous system during early development and in the mature animal. J Lipid Res 45: $1375-1397$.

Dill J, Wang H, Zhou F, Li S (2008). Inactivation of glycogen synthase kinase 3 promotes axonal growth and recovery in the CNS. J Neurosci 28: 8914-8928.

Du J, Wei Y, Liu L, Wang Y, Khairova R, Blumenthal R et al (2010). A kinesin signaling complex mediates the ability of GSK-3beta to affect mood-associated behaviors. Proc Natl Acad Sci USA 107: 11573-11578.

Dubois J, Dehaene-Lambertz G, Perrin M, Mangin JF, Cointepas Y, Duchesnay E et al (2008). Asynchrony of the early maturation of 
white matter bundles in healthy infants: quantitative landmarks revealed noninvasively by diffusion tensor imaging. Hum Brain Mapp 29: 14-27.

Fancy SP, Baranzini SE, Zhao C, Yuk DI, Irvine KA, Kaing S et al (2009). Dysregulation of the Wnt pathway inhibits timely myelination and remyelination in the mammalian CNS. Genes Dev 23: 1571-1585.

Feigenson K, Reid M, See J, Crenshaw EB 3rd, Grinspan JB (2009). Wnt signaling is sufficient to perturb oligodendrocyte maturation. Mol Cell Neurosci 42: 255-265.

Forde JE, Dale TC (2007). Glycogen synthase kinase 3: a key regulator of cellular fate. Cell Mol Life Sci 64: 1930-1944.

Gould TD, Manji HK (2005). Glycogen synthase kinase-3: a putative molecular target for lithium mimetic drugs. Neuropsychopharmacology 30: 1223-1237.

Grimes CA, Jope RS (2001a). CREB DNA binding activity is inhibited by glycogen synthase kinase-3 beta and facilitated by lithium. J Neurochem 78: 1219-1232.

Grimes CA, Jope RS (2001b). The multifaceted roles of glycogen synthase kinase 3beta in cellular signaling. Prog Neurobiol 65: 391-426.

Harsan LA, Poulet P, Guignard B, Steibel J, Parizel N, de Sousa PL et al (2006). Brain dysmyelination and recovery assessment by noninvasive in vivo diffusion tensor magnetic resonance imaging. J Neurosci Res 83: 392-402.

Herting MM, Maxwell EC, Irvine C, Nagel BJ (2011). The Impact of Sex, Puberty, and Hormones on white matter microstructure in adolescents. Cereb Cortex 22: 1979-1992.

Hill T, Lewicki P (2006). Statistics: methods and applications. A comprehensive reference for science, industry, and data mining. General Linear Models Chapter 18, StatSoft: Tulsa, OK, 245-276.

Houenou J, Wessa M, Douaud G, Leboyer M, Chanraud S, Perrin M et al (2007). Increased white matter connectivity in euthymic bipolar patients: diffusion tensor tractography between the subgenual cingulate and the amygdalo-hippocampal complex. Mol Psychiatry 12: 1001-1010.

Iitaka C, Miyazaki K, Akaike T, Ishida N (2005). A role for glycogen synthase kinase-3beta in the mammalian circadian clock. J Biol Chem 280: 29397-29402.

Inkster B, Nichols TE, Saemann PG, Auer DP, Holsboer F, Muglia P et al (2009). Association of GSK3beta polymorphisms with brain structural changes in major depressive disorder. Arch Gen Psychiatry 66: 721-728.

Inkster B, Nichols TE, Saemann PG, Auer DP, Holsboer F, Muglia P et al (2010). Pathway-based approaches to imaging genetics association studies: Wnt signaling, GSK3beta substrates and major depression. Neuroimage 53: 908-917.

Italia J, Mukhopadhyaya R, Rajadhyaksha MS (2011). Differential display RT-PCR reveals genes associated with lithium-induced neuritogenesis in SK-N-MC cells. Cell Mol Neurobiol 31: 1021-1026.

Jenkinson M, Smith S (2001). A global optimisation method for robust affine registration of brain images. Med Image Anal 5: $143-156$

Jiang H, Guo W, Liang X, Rao Y (2005). Both the establishment and the maintenance of neuronal polarity require active mechanisms: critical roles of GSK-3beta and its upstream regulators. Cell 120: 123-135.

Jope RS (1999). Anti-bipolar therapy: mechanism of action of lithium. Mol Psychiatry 4: 117-128.

Jope RS (2003). Lithium and GSK-3: one inhibitor, two inhibitory actions, multiple outcomes. Trends Pharmacol Sci 24: 441-443.

Keedwell PA, Chapman R, Christiansen K, Richardson H, Evans J, Jones DK (2012). Cingulum white matter in young women at risk of depression: the effect of family history and anhedonia. Biol Psychiatry 72: 196-302.

Kinoshita Y, Ohnishi A, Kohshi K, Yokota A (1999). Apparent diffusion coefficient on rat brain and nerves intoxicated with methylmercury. Environ Res 80: 348-354.
Kochunov P, Thompson PM, Lancaster JL, Bartzokis G, Smith S, Coyle $\mathrm{T}$ et al (2007). Relationship between white matter fractional anisotropy and other indices of cerebral health in normal aging: tract-based spatial statistics study of aging. Neuroimage 35: 478-487.

Kockeritz L, Doble B, Patel S, Woodgett JR (2006). Glycogen synthase kinase-3-an overview of an over-achieving protein kinase. Curr Drug Targets 7: 1377-1388.

Kondratov RV, Shamanna RK, Kondratova AA, Gorbacheva VY, Antoch MP (2006). Dual role of the CLOCK/BMAL1 circadian complex in transcriptional regulation. FASEB J 20: 530-532.

Kwok JB, Hallupp M, Loy CT, Chan DK, Woo J, Mellick GD et al (2005). GSK3B polymorphisms alter transcription and splicing in Parkinson's disease. Ann Neurol 58: 829-839.

Le Bihan D (2003). Looking into the functional architecture of the brain with diffusion MRI. Nat Rev Neurosci 4: 469-480.

Lebel C, Gee M, Camicioli R, Wieler M, Martin W, Beaulieu C (2012). Diffusion tensor imaging of white matter tract evolution over the lifespan. Neuroimage 60: 340-352.

Leckman JFSD, Thompson WD, Belanger A, Weissman MM (1982). Best estimate of lifetime psychiatric diagnosis: a methodological study. Arch Gen Psychiatry 39: 879-883.

Leyhe T, Eschweiler GW, Stransky E, Gasser T, Annas P, Basun H et al (2009). Increase of BDNF serum concentration in lithium treated patients with early Alzheimer's disease. J Alzheimers Dis 16: 649-656.

Lu LH, Zhou XJ, Keedy SK, Reilly JL, Sweeney JA (2011). White matter microstructure in untreated first episode bipolar disorder with psychosis: comparison with schizophrenia. Bipolar Disord 13: 604-613.

Lyoo IK, Dager SR, Kim JE, Yoon SJ, Friedman SD, Dunner DL et al (2010). Lithium-induced gray matter volume increase as a neural correlate of treatment response in bipolar disorder: a longitudinal brain imaging study. Neuropsychopharmacology 35: $1743-1750$

Manji HK, Drevets WC, Charney DS (2001). The cellular neurobiology of depression. Nat Med 7: 541-547.

Manji HK, Moore GJ, Rajkowska G, Chen G (2000). Neuroplasticity and cellular resilience in mood disorders. Mol Psychiatry 5: 578-593.

Matsuo K, Nielsen N, Nicoletti MA, Hatch JP, Monkul ES, Watanabe $\mathrm{Y}$ et al (2010). Anterior genu corpus callosum and impulsivity in suicidal patients with bipolar disorder. Neurosci Lett 469: 75-80.

McCulloch CE, Searle SR, Neuhaus JM (2008). Generalized, Linear, and Mixed Models. Second Edition John Wiley \& Sons.

Mizutani R, Yamauchi J, Kusakawa S, Nakamura K, Sanbe A, Torii $\mathrm{T}$ et al (2009). Sorting nexin 3, a protein upregulated by lithium, contains a novel phosphatidylinositol-binding sequence and mediates neurite outgrowth in N1E-115 cells. Cell Signal 21: $1586-1594$.

Monkul ES, Matsuo K, Nicoletti MA, Dierschke N, Hatch JP, Dalwani $M$ et al (2007). Prefrontal gray matter increases in healthy individuals after lithium treatment: a voxel-based morphometry study. Neurosci Lett 429: 7-11.

Moore GJ, Cortese BM, Glitz DA, Zajac-Benitez C, Quiroz JA, Uhde TW et al (2009). A longitudinal study of the effects of lithium treatment on prefrontal and subgenual prefrontal gray matter volume in treatment-responsive bipolar disorder patients. J Clin Psychiatry 70: 699-705.

Namekata K, Harada C, Guo X, Kimura A, Kittaka D, Watanabe H et al (2012). Dock3 stimulates axonal outgrowth via GSK-3beta-mediated microtubule assembly. J Neurosci 32: 264-274.

Nanavati D, Austin DR, Catapano LA, Luckenbaugh DA, Dosemeci A, Manji HK et al (2011). The effects of chronic treatment with mood stabilizers on the rat hippocampal post-synaptic density proteome. J Neurochem 119: 617-629. 
Nichols TE, Holmes AP (2002). Nonparametric permutation tests for functional neuroimaging: a primer with examples. Hum Brain Mapp 15: 1-25.

Ogata T, Iijima S, Hoshikawa S, Miura T, Yamamoto S, Oda $\mathrm{H}$ et al (2004). Opposing extracellular signal-regulated kinase and Akt pathways control Schwann cell myelination. J Neurosci 24: 6724-6732.

Oldfield RC (1971). The assessment and analysis of handedness: the Edinburgh inventory. Neuropsychologia 9: 97-113.

Pende M, Fisher TL, Simpson PB, Russell JT, Blenis J, Gallo V (1997). Neurotransmitter- and growth factor-induced cAMP response element binding protein phosphorylation in glial cell progenitors: role of calcium ions, protein kinase $\mathrm{C}$, and mitogenactivated protein kinase/ribosomal S6 kinase pathway. J Neurosci 17: 1291-1301.

Qiu D, Tan LH, Zhou K, Khong PL (2008). Diffusion tensor imaging of normal white matter maturation from late childhood to young adulthood: voxel-wise evaluation of mean diffusivity, fractional anisotropy, radial and axial diffusivities, and correlation with reading development. Neuroimage 41: 223-232.

Quiroz JA, Machado-Vieira R, Zarate CA Jr., Manji HK (2010). Novel insights into lithium's mechanism of action: neurotrophic and neuroprotective effects. Neuropsychobiology 62: 50-60.

Rajkowska G (2002). Cell pathology in bipolar disorder. Bipolar Disord 4: 105-116.

Rich BA, Fromm SJ, Berghorst LH, Dickstein DP, Brotman MA, Pine DS et al (2008). Neural connectivity in children with bipolar disorder: impairment in the face emotion processing circuit. J Child Psychol Psychiatry 49: 88-96.

Rueckert D, Sonoda LI, Hayes C, Hill DL, Leach MO, Hawkes DJ (1999). Nonrigid registration using free-form deformations: application to breast MR images. IEEE Trans Med Imaging 18: 712-721.

Russ C, Lovestone S, Powell JF (2001). Identification of sequence variants and analysis of the role of the glycogen synthase kinase 3 beta gene and promoter in late onset Alzheimer's disease. Molecular Psychiatry 6: 320-324.

Saxena K, Tamm L, Walley A, Simmons A, Rollins N, Chia J et al (2012). A preliminary investigation of corpus callosum and anterior commissure aberrations in aggressive youth with bipolar disorders. J Child Adolesc Psychopharmacol 22: 112-119.

Schermuly I, Fellgiebel A, Wagner S, Yakushev I, Stoeter P, Schmitt $\mathrm{R}$ et al (2010). Association between cingulum bundle structure and cognitive performance: an observational study in major depression. Eur Psychiatry 25: 355-360.

Schloesser RJ, Martinowich K, Manji HK (2011). Mood-stabilizing drugs: mechanisms of action. Trends Neurosci 35: 36-46.

Sexton CE, Mackay CE, Lonie JA, Bastin ME, Terriere E, O'Carroll $\mathrm{RE}$ et al (2010). MRI correlates of episodic memory in Alzheimer's disease, mild cognitive impairment, and healthy aging. Psychiatry Res 184: 57-62.

Sexton CE, McDermott L, Kalu UG, Herrmann LL, Bradley KM, Allan CL et al (2011). Exploring the pattern and neural correlates of neuropsychological impairment in late-life depression. Psychol Med 42: 1195-1202.

Small SA, Schobel SA, Buxton RB, Witter MP, Barnes CA (2011). A pathophysiological framework of hippocampal dysfunction in ageing and disease. Nat Rev Neurosci 12: 585-601.

Smith SM (2002). Fast robust automated brain extraction. Hum Brain Mapp 17: 143-155.

Smith SM, Jenkinson M, Johansen-Berg H, Rueckert D, Nichols TE, Mackay CE et al (2006). Tract-based spatial statistics: voxelwise analysis of multi-subject diffusion data. Neuroimage 31: 1487-1505.

Smith SM, Jenkinson M, Woolrich MW, Beckmann CF, Behrens TE, Johansen-Berg $\mathrm{H}$ et al (2004). Advances in functional and structural MR image analysis and implementation as FSL. Neuroimage 23(Suppl 1): S208-S219.
Smith SM, Johansen-Berg H, Jenkinson M, Rueckert D, Nichols TE, Miller KL et al (2007). Acquisition and voxelwise analysis of multi-subject diffusion data with tract-based spatial statistics. Nat Protoc 2: 499-503.

Smith SM, Nichols TE (2009). Threshold-free cluster enhancement: addressing problems of smoothing, threshold dependence and localisation in cluster inference. Neuroimage 44: 83-98.

Song SK, Sun SW, Ju WK, Lin SJ, Cross AH, Neufeld AH (2003). Diffusion tensor imaging detects and differentiates axon and myelin degeneration in mouse optic nerve after retinal ischemia. Neuroimage 20: 1714-1722.

Song SK, Sun SW, Ramsbottom MJ, Chang C, Russell J, Cross AH (2002). Dysmyelination revealed through MRI as increased radial (but unchanged axial) diffusion of water. Neuroimage 17: $1429-1436$.

Sprooten E, Sussmann JE, Clugston A, Peel A, McKirdy J, Moorhead TW et al (2011). White matter integrity in individuals at high genetic risk of bipolar disorder. Biol Psychiatry 70: 350-356.

Su H, Zhang W, Guo J, Guo A, Yuan Q, Wu W (2009). Lithium enhances the neuronal differentiation of neural progenitor cells in vitro and after transplantation into the avulsed ventral horn of adult rats through the secretion of brain-derived neurotrophic factor. J Neurochem 108: 1385-1398.

Sun SW, Liang HF, Trinkaus K, Cross AH, Armstrong RC, Song SK (2006). Noninvasive detection of cuprizone induced axonal damage and demyelination in the mouse corpus callosum. Magn Reson Med 55: 302-308.

Suzuki S, Kiyosue K, Hazama S, Ogura A, Kashihara M, Hara T et al (2007). Brain-derived neurotrophic factor regulates cholesterol metabolism for synapse development. J Neurosci 27: 6417-6427.

Takahashi M, Ono J, Harada K, Maeda M, Hackney DB (2000). Diffusional anisotropy in cranial nerves with maturation: quantitative evaluation with diffusion $\mathrm{MR}$ imaging in rats. Radiology 216: 881-885.

Taylor WD, Hsu E, Krishnan KR, MacFall JR (2004). Diffusion tensor imaging: background, potential, and utility in psychiatric research. Biol Psychiatry 55: 201-207.

Timm N, Kim K (2006). Univariate and Multivariate General Linear Models: Theory and Applications with SAS, Second Edition. Springer: Berlin/Heidelberg.

Tkachev D, Mimmack ML, Ryan MM, Wayland M, Freeman T, Jones PB et al (2003). Oligodendrocyte dysfunction in schizophrenia and bipolar disorder. Lancet 362: 798-805.

Uranova NA, Vostrikov VM, Orlovskaya DD, Rachmanova VI (2004). Oligodendroglial density in the prefrontal cortex in schizophrenia and mood disorders: a study from the Stanley Neuropathology Consortium. Schizophr Res 67: 269-275.

van der Schot AC, Vonk R, Brans RG, van Haren NE, Koolschijn PC, Nuboer V et al (2009). Influence of genes and environment on brain volumes in twin pairs concordant and discordant for bipolar disorder. Arch Gen Psychiatry 66: 142-151.

Vik-Mo AO, Ferno J, Skrede S, Steen VM (2009). Psychotropic drugs up-regulate the expression of cholesterol transport proteins including ApoE in cultured human CNS- and liver cells. BMC Pharmacol 9: 10.

VonDran MW, Singh H, Honeywell JZ, Dreyfus CF (2011). Levels of BDNF impact oligodendrocyte lineage cells following a cuprizone lesion. J Neurosci 31: 14182-14190.

Walther S, Hugli S, Hofle O, Federspiel A, Horn H, Bracht T et al (2012). Frontal white matter integrity is related to psychomotor retardation in major depression. Neurobiol Dis 47: 13-19.

Wang S, Sdrulla AD, diSibio G, Bush G, Nofziger D, Hicks C et al (1998). Notch receptor activation inhibits oligodendrocyte differentiation. Neuron 21: 63-75. 
Wang Z, Wang J, Li J, Wang X, Yao Y, Zhang X et al (2011). MEK/ ERKs signaling is essential for lithium-induced neurite outgrowth in N2a cells. Int J Dev Neurosci 29: 415-422.

Wessa M, Houenou J, Leboyer M, Chanraud S, Poupon C, Martinot $\mathrm{JL}$ et al (2009). Microstructural white matter changes in euthymic bipolar patients: a whole-brain diffusion tensor imaging study. Bipolar Disord 11: 504-514.

Westlye LT, Walhovd KB, Dale AM, Bjornerud A, Due-Tonnessen P, Engvig A et al (2010). Life-span changes of the human brain white matter: diffusion tensor imaging (DTI) and volumetry. Cereb Cortex 20: 2055-2068.

Woolrich MW, Jbabdi S, Patenaude B, Chappell M, Makni S, Behrens $\mathrm{T}$ et al (2009). Bayesian analysis of neuroimaging data in FSL. Neuroimage 45(1 Suppl): S173-S186.

Yoshimura T, Arimura N, Kawano Y, Kawabata S, Wang S, Kaibuchi K (2006). Ras regulates neuronal polarity via the PI3-kinase/Akt/GSK-3beta/CRMP-2 pathway. Biochem Biophys Res Commun 340: $62-68$.
Yoshimura T, Kawano Y, Arimura N, Kawabata S, Kikuchi A, Kaibuchi K (2005). GSK-3beta regulates phosphorylation of CRMP-2 and neuronal polarity. Cell 120: 137-149.

Yuskaitis CJ, Jope RS (2009). Glycogen synthase kinase-3 regulates microglial migration, inflammation, and inflammation-induced neurotoxicity. Cell Signal 21: 264-273.

Zhang A, Leow A, Ajilore O, Lamar M, Yang S, Joseph J et al (2012). Quantitative tract-specific measures of uncinate and cingulum in major depression using diffusion tensor imaging. Neuropsychopharmacology 37: 959-967.

Zhang W, Smith A, Liu JP, Cheung NS, Zhou S, Liu K et al (2009). GSK3beta modulates PACAP-induced neuritogenesis in PC12 cells by acting downstream of Rap1 in a caveolae-dependent manner. Cell Signal 21: 237-245.

Zhou FQ, Zhou J, Dedhar S, Wu YH, Snider WD (2004). NGFinduced axon growth is mediated by localized inactivation of GSK-3beta and functions of the microtubule plus end binding protein APC. Neuron 42: 897-912. 